\title{
Rancang Bangun Web Aplikasi Pergi Bareng Sebagai Media Perencanaan Perjalanan dan Komunikasi Menggunakan Metode Agile Berbasis Cloud computing
}

\author{
R Dimas Adityo ${ }^{1}$, Ragil Prasetiyo ${ }^{2}$ \\ 1,2 Program Studi Teknik Informatika, Universitas Bhayangkara Surabaya \\ Email: ${ }^{1}$ dimas@ubhara.ac.id, ${ }^{2}$ ragilae02@gmail.com
}

\begin{abstract}
Abstrak: PERGI BARENG merupakan sistem aplikasi yang dikembangkan untuk menampung suatu bentuk perencanaan perjalanan dan komunikasi yang dilakukan oleh para penggiat perjalanan, sehingga suatu rencana perjalanan dapat dilakukan secara bersamaan atau bersama-sama. Pengembangan sistem aplikasi berjalan seiring menggunakan metode agile dengan pendekatan model Extreme Programming (XP). Proses penyebaran tercepat sesuai dengan kebutuhan pengembangan sistem, platform komputasi awan digunakan sebagai media penyebaran. Pengembangan sistem dilakukan dalam beberapa tahap pengembangan yaitu tahap perencanaan, perancangan, pengembangan (coding), dan pengujian yang dilakukan sesuai dengan prinsip metode agile. Hasil pengujian alpha menjelaskan bahwa secara keseluruhan sistem yang dibangun telah berhasil atau diterima, karena secara fungsional sistem dapat berjalan sesuai dengan yang diharapkan. Dari hasil pengujian beta variabel efisiensi sebesar $88 \%$, variabel efektif $83 \%$, dan variabel kepuasan $87 \%$. Berdasarkan pengujian terhadap 3 indikator tersebut didapatkan nilai usability sistem sebesar $85 \%$. Sehingga dapat disimpulkan bahwa perancangan sistem aplikasi berjalan bersama menggunakan metode agile dengan pendekatan Extreme Programming cocok untuk para penggiat wisata. Diperlukan pengembangan sistem lebih lanjut agar sistem dapat berjalan dengan baik.
\end{abstract}

Kata Kunci: Metode Agile, Extreme Programming, Rancang Bangun Web Aplikasi, Pergi Bareng

\begin{abstract}
PERGI BARENG is an application system developed to accommodate a form of travel planning and communication carried out by travel activists, so that a trip plan can be carried out simultaneously or together. Development of application systems goes hand in hand using the agile method with the Extreme Programming (XP) model approach. The fastest deployment process according to system development needs, cloud computing platforms are used as the deployment media. System development is carried out in several stages of development, namely the planning, design, development (coding), and testing stages which are carried out in accordance with the principles of the agile method. The results of alpha testing explain that the overall system built has been successful or accepted, because functionally the system can run as expected. From the results of beta testing of the variable efficiency is $88 \%$, the effectiveness variable is $83 \%$, and the variable satisfaction is $87 \%$. Based on the testing of these 3 indicators, the usability value of the system is $85 \%$. So it can be concluded that the design of the application system to go together using the agile method with the Extreme Programming approach is suitabel for travel activists. Further system development is needed so that the system can run properly.
\end{abstract}

Keywords: Metode Agile, Extreme Programming, Design Web Application Development, Pergi Bareng

\section{PENDAHULUAN}

Suatu perencanaan yang matang merupakan hal yang terpenting ketika akan melakukan suatu kegiatan perjalanan. Agar rencana perjalanan dapat berjalan dengan seperti yang diinginkan. Tidak semua orang bisa melakukan perjalanan dan melakukan kegiatan secara bersama-sama. Bagaimana rencana perjalanan yang akan dibuat nantinya bisa dilihat dan bisa diikuti oleh orang lain yang ingin melakukan rencana perjalanan dan kegiatan di waktu dan tempat yang sama. Saat ini perkembangan teknologi di dunia yang semakin berkembang. Sebuah sistem dapat dikembangkan dengan mudah dan cepat. Salah satunya di bidang tekologi pengembangan perangkat lunak. Mulai dari sistem aplikasi untuk desktop sampai ke perangkat smarthphone. Sistem operasi Android, iOS [1], dan cross platform merupakan bidang yang banyak dikerjakan oleh pihak developer aplikasi, 50\% developer aplikasi memiliki gagasan untuk membuat aplikasi dan startup. Sistem operasi Android, iOS, dan cross platform merupakan bidang yang banyak dikerjakan oleh pihak developer aplikasi, 50\% developer aplikasi memiliki gagasan untuk membuat aplikasi dan startup. Ada banyak metode yang membuat sebuah sistem aplikasi sesuai dengan kebutuhan. Salah satunya metode Agile. Metode agile merupkan sekumpulan metode pengembangan perangkat lunak mengedapankan kecepatan dan kemudahan dalam pengembangan sistem perangkat lunak. Untuk memenuhi kebutuhan suatu rencana kegiatan perjalanan agar rencana perjalanan tersebut dapat dilakukan dengan berbarengan bersama 
orang lain atau partner perjalanan, dirancanglah sebuah sistem web aplikasi Pergi Bareng sebagai media perencanaan perjalanan dan komunikasi menggunakan metode agile berbasis cloud computing.

Tujuan penelitian ini adalah merancang dan membangun web aplikasi Pergi Bareng sebagai media perencanaan dan komunikasi untuk memudahkan orang bertemu dalam rencana, tujuan dan kegiatan yang sama. Agar orang yang akan melakukan rencana kegiatan atau tujuan tersebut tidak dilakukan sendiri atau dapat dilakukan berbarengan. Sekaligus juga menambah relasi pertemanan. Cloud computing digunakan untuk mengembangkan aplikasi Pergi Bareng. Menghindari adanya penyimpangan maupun pelebaran pokok masalah agar penelitian ini lebih terarah dan memudahkan dalam pembahasan sehingga tujuan penelitian akan tercapai. Beberapa batasan masalah dalam penelitian ini adalah sebagai berikut :

1. Cloud computing menggunakan Google Cloud Platform[2].

2. Peneliti tidak membahas keamanan sistem.

3. Sebagian kota - kota besar yang ada di pulau jawa dijadikan sebagai cakupan area tujuan dalam pengembangan penelitian ini. Meliputi kota Surabaya, Malang, Yogyakarta, Solo, Semarang, Bandung, dan Jakarta.

Penelitian dilakukan menggunakan Metode Agile. Teknik pengembangan sistem yang terdiri dari perencanaan (planning), perancangan (design), pengembangan (coding) dan pengujian (testing). Teknik pengujian sistem menggunakan pengujian alpha dan beta. Gambar 1 menggambarkan tahapan pengembangan metode agile.

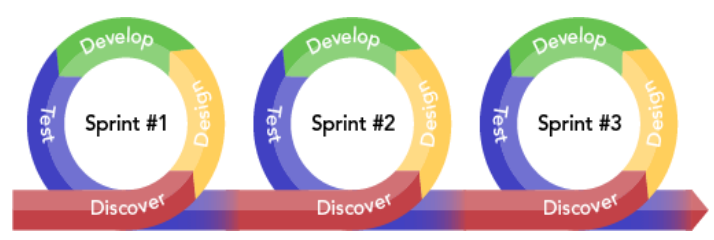

Gambar 1 Tahap Metode Agile

Teknologi web telah merubah cara organisasi dalam menjalankan bisnis dan komunikasi. Untuk pengembangan aplikasi, teknologi web telah menyajikan dunia baru dari rekayasa perangkat lunak (software engineering) dengan teknik - teknik baru, tool baru, lingkungan perancangan, dan penyebaran yang baru. Teknologi ini juga memungkinkan organisasi untuk menyampaikan aplikasi web dengan lebih mudah dan lebih cepat serta menyediakan metode yang lebih efisien untuk melakukan pemeliharaan. Sebagai hasilnya, organisasi lebih tanggap terhadap kebutuhan pengguna dan lebih cepat untuk menyesuaikan aplikasi kepada pengguna yang lebih spesifik [3].

Dalam rekayasa perangkat lunak, suatu aplikasi web adalah suatu aplikasi yang diakses menggunakan penjelajah web melalui suatu jaringan seperti internet atau intranet. Ia juga merupakan suatu aplikasi perangkat lunak komputer yang dikodekan dalam bahasa yang didukung penjelajah web (seperti ASP, Perl, Java, Java Script, PHP, Python, Ruby, dll) dan bergantung pada penjelajah tersebut untuk menampilkan aplikasi [5].

\section{Usabilitas Aplikasi Web}

Usabilitas adalah salah satu faktor kualitas yang paling penting untuk aplikasi Web. Usabilitas yang kurang pada aplikasi akan menyebabkan pengguna tidak dapat mengoperasikannya, terutama pada aplikasi Web. Tujuan utama adalah untuk merancang aplikasi Web, kita harus mempertimbangkan konteks kebutuhan pengguna dan pemakaian umum. Selain itu, kita juga harus menentukan cara manusia memproses informasi, persepsi, memori, dan perhatian yang mempengaruhi interaksi.

\section{Metode Agile}

Agile Development Methods adalah sekelompok metodologi pengembangan perangkat lunak yang didasarkan pada prinsip-prinsip yang sama atau pengembangan sistem jangka pendek yang memerlukan adaptasi cepat dari pengembang terhadap perubahan dalam bentuk apapun. Agile development methods merupakan salah satu dari Metodologi pengembangan perangkat lunak yang digunakan dalam pengembangan perangkat lunak.

Agile merupakan pendekatan yang iterative dan evolusioner yang dilakukan dengan mengedepankan kolaborasi serta menggunakan dokumen formal yang terbatas dan tepat untuk membangun perangkat lunak yang berkualitas dalam hal biaya yang efektif serta waktu yang sesuai dengan kebubtuhan stakeholder yang bisa berubah - ubah[4].

Agile Alliance, mendefinisikan 12 prinsip untuk mencapai proses yang termasuk dalam agility [5], yaitu:

1. Prioritas utama adalah memuaskan klien dengan menghasilkan perangkat lunak secara cepat.

2. Klien dengan menghasilkan perangkat lunak secara cepat.

3. Menyambut perubahan kebutuhan walaupun terlambat dalam pengembangan perangkat lunak. Proses Agile memanfaatkan perubahan untuk keuntungan kompetitif klien.

4. Menghasilkan perangkat lunak yang bekerja secara rutin dari jangka waktu beberapa minggu sampai beberapa bulan dengan preferensi kepada jangka waktu yang lebih pendek.

5. Rekan bisnis dan pengembang perangkat lunak harus bekerja sama setiap hari dan sepanjang proyek.

6. Mengembangkan proyek di sekitar individual 
yang termotivasi. Memberi lingkungan dan dukungan yang dibutuhkan dan mempercayai untuk menyelesaikan pekerjaan dengan baik.

7. Metode yang paling efisien dan efektif untuk menyampaikan informasi dari dan dalam tim pengembangan perangkat lunak adalah dengan komunikasi secara langsung.

8. Perangkat lunak yang bekerja adalah ukuran utama kemajuan.

9. Proses Agile menggalakkan pengembangan berkelanjutan. Sponsor, pengembang, dan pengguna akan dapat mempertahankan kecepatan tetap secara berkelanjutan.

10. Perhatian yang berkesinambungan terhadap keunggulan teknis dan rancangan yang baik meningkatkan Agility.

11. Kesederhanaan adalah hal sangat yang amat penting.

12. Arsitektur, kebutuhan, dan rancangan perangkat lunak terbaik muncul dari tim yang yang dapat mengorganisir diri sendiri.

13. Secara berkala, tim pengembang berefleksi tentang bagaimana untuk menjadi lebih efektif kemudian menyesuaikan dan menyelaraskan kebiasaan bekerjanya.

\section{Extreme Programming}

Extreme programming (XP) adalah model dari pengembangan perangkat lunak dari metode agile. XP sangat cocok untuk pengembangan proyek yang memerlukan adaptasi cepat dalam perubahanperubahan yang terjadi selama pengembangan aplikasi. XP juga cocok untuk anggota tim yang tidak terlalu banyak dan berada pada lokasi yang sama dalam pengembangan sistem [6].

\section{Cloud computing}

Cloud computing merupakan evolusi yang mengadopsi virtualization, service-oriented architecture and utility computing. Cloud computing memungkinkan konsumen teknologi untuk memikirkan komputasi secara efektif dengan biaya minimal dan dapat diandalkan.

\section{Pengujian Alpha dan Beta}

Pengujian dilakukan karena memungkinkan pelanggan menemukan kesalahan yang lebih rinci dan membiasakan pelanggan memahami perangkat lunak yang telah dibuat. Pengujian Alpha berfokus pada persyaratan fungsionalitas dari perangkat lunak [7]. Pengujian beta merupakan pengujian yang dilakukan secara objektif, dimana pengujian dilakukan secara langsung terhadap pengguna, dengan memberikan kuesioner mengenai tanggapan pengguna atas perangkat lunak yang telah dibangun. Pengujian beta dilakukan terhadap usability sistem [7].

Untuk mengukur persentase pencapaian dan klafikasi kelayakan dapat diukur dengan skala pengukuran produk sebagai berikut:

Tabel 1 Draft Pengukuran

\begin{tabular}{c|c|l}
\hline No & $\begin{array}{c}\text { Persentase } \\
\text { Pencapaian }\end{array}$ & Klafikasi Kelayakan \\
\hline 1 & $8 \%-100 \%$ & Sangat Layak \\
\hline 2 & $61 \%-80 \%$ & Layak \\
\hline 3 & $41 \%-60 \%$ & Cukup Layak \\
\hline 4 & $21 \%-40 \%$ & Tidak Layak \\
\hline 5 & $0 \%-20 \%$ & Sangat Tidak Layak \\
\hline
\end{tabular}

\section{Metode Penelitian}

Penelitian Rancang Bangun Web Aplikasi Pergi Bareng berbasis Cloud computing dilakukan dengan langkah - langkah sebagai berikut:

\section{Perencanaan (Planning)}

Proses perencanaan dilakukan dengan mengevaluasi masalah latar belakang pengembangan sistem, yang dilakukan dengn wawancara dengan salah satu pegiat perjalanan wisata.

2. Perancangan (Design)

Pembuatan rancangan sistem yang nantinya digunakan sebagai perbandingan input dan output sistem sesuai dengan tujuan yang diharapkan.

3. Pengembangan (Coding)

Pengembangan sistem yang dibangun yaitu rancang bangun web aplikasi berbasis Cloud Computing

4. Pengujian (Testing)

Pengujian dilakukan dengan menggunakan pengujian Alpha dan Beta.

\section{Perencanaan Sistem Flowchart Sistem}

Flowchart sistem aplikasi Pergi Bareng dapat dilihat pada gambar 2 dan gambar 3

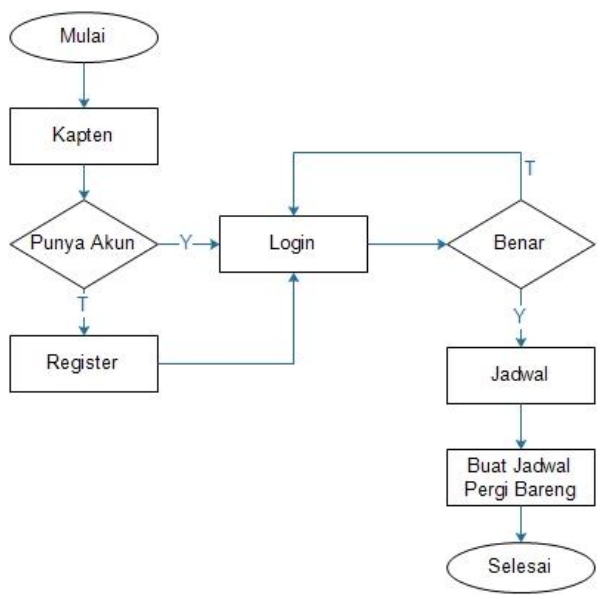

Gambar 2 Flowchart Kapten 
Flowchart Kapten adalah proses kerja Kapten untuk membuat jadwal perjalanan dimana Kapten harus melakukan register dulu kemudian login, setelah berhasil login, Kapten dapat membuat jadwal perjalanan Pergi Bareng.

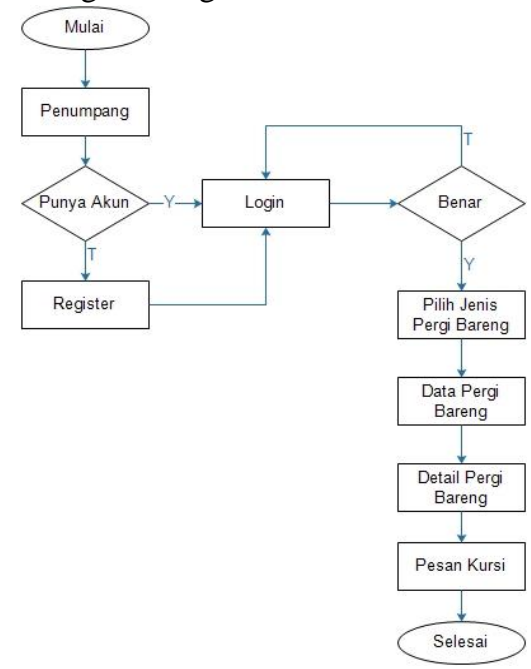

Gambar 3 Flowchart Penumpang

Flowchart Penumpang adalah proses kerja Penumpang untuk memesan kursi dimana Penumpang harus melakukan register dulu kemudian login, setelah berhasil login, Penumpang dapat memilih jenis perjalanan kumudian melihat data perjalanan setelah itu Penumpang dapat melihat detail perjalanan dan memesan kursi perjalanan tersebut.

\section{Data Flow Diagram Level 0}

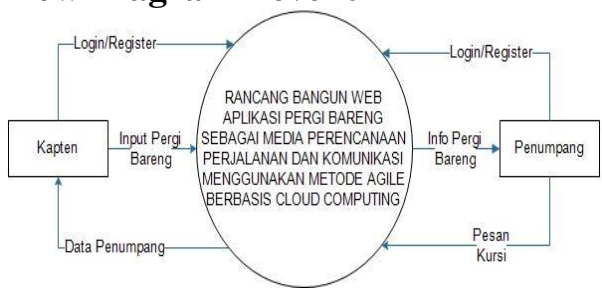

Gambar 4 Data Flow Diagram Level 0

Data Flow Diagram Level 0 atau Diagram Konteks merupakan tingkatan tertinggi dalam diagram aliran data dan hanya memuat satu proses, menunjukkan sistem secara keseluruhan.

Pada diagram konteks terdapat dua entitas yaitu Kapten dan Penumpang. Entitas Kapten berfungsi untuk menginput data perjalanan Pergi Bareng dan melihat data Penumpang yang memesan kursi perjalanan Pergi Bareng, entitas Penumpang dapat melihat informasi perjalanan Pergi Bareng dan memesan kursi pada Kapten jika perjalanan satu tujuan. Kedua entitas tersebut harus membuat akun dan login sebelum menggunakan aplikasi.

\section{Data Flow Diagram Level 1}

Dari Gambar 5 Data Flow Diagram level 1, Member Kapten dan Penumpang harus register dan login ke sistem. Kapten membuat jadwal Pergi Bareng. Data
Pergi Bareng akan disimpan dan akan ditampilkan di info Pergi Bareng. Member Penumpang mencari informasi data jadwal Pergi Bareng yang dibuat oleh member Kapten. Member Penumpang pesan kursi. Info detail bareng disimpan di data Penumpang, kemudian menghasilkan informasi data Penumpang yang memesan kursi atau gabung perjalanan.

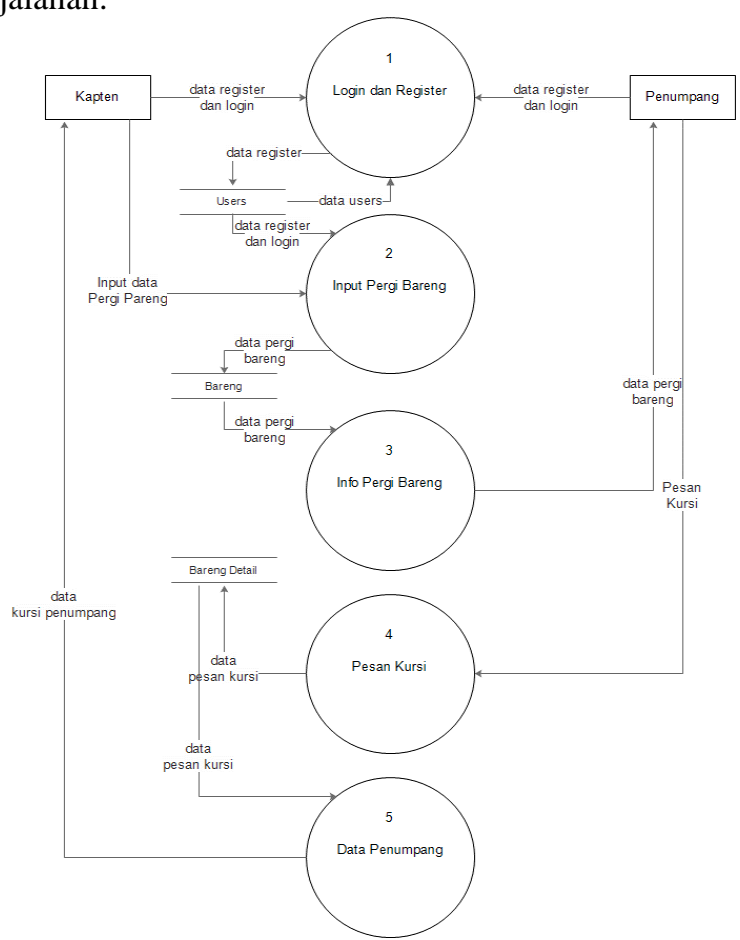

Gambar 5 Data Flow Diagram Level 1

\section{Data Flow Diagram Level 2 Proses 1}

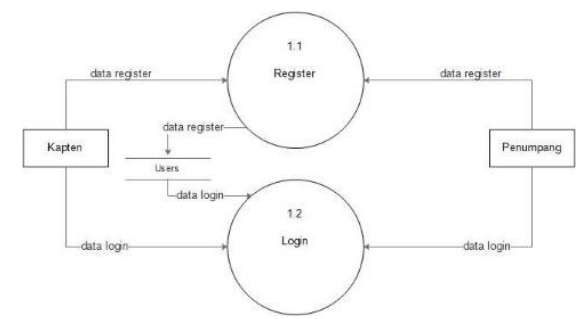

Gambar 6 Data Flow Diagram Level 2 Proses I

Dari Gambar 6 Data Flow Diagram level 2 Proses 1 adalah proses yang dilakukan Kapten dan Penumpang untuk mendaftar dan login di aplikasi Pergi Bareng, data register dan login disimpan pada tabel users. 


\section{Data Flow Diagram Level 2 Proses 2}

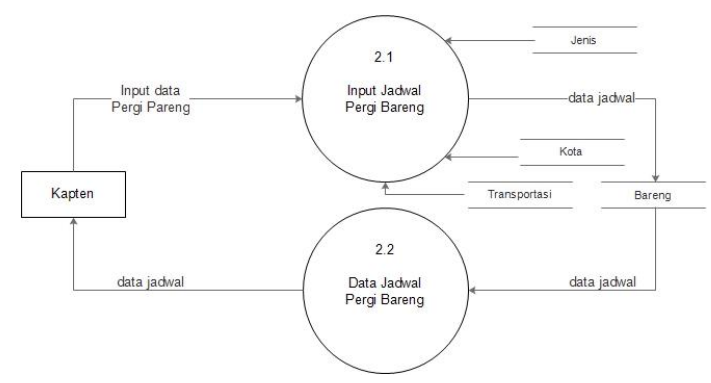

Gambar 7 Data Flow Diagram Level 2 Proses 2

Berdasarkan Gambar 7 Data Flow Diagram Level 2 Proses 2 adalah proses input Pergi Bareng yang dilakukan Kapten untuk menambah data perjalanan, data ini disimpan pada tabel Pergi Bareng dengan mengambil id Kapten pada tabel users.

\section{Data Flow Diagram Level 2 Proses 3}

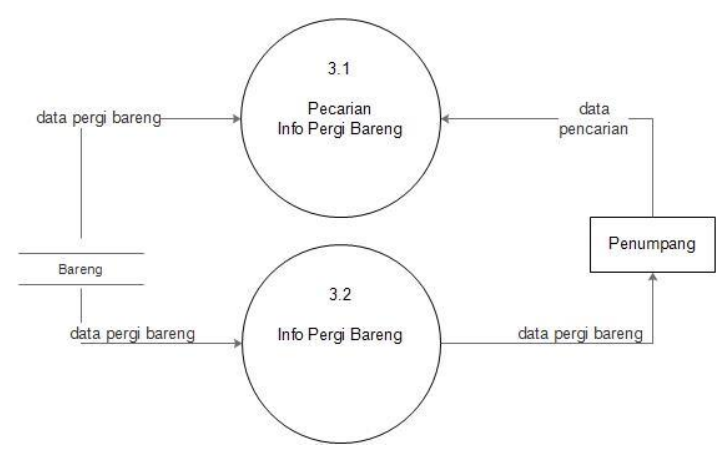

Gambar 8 Data Flow Diagram Level 2 Proses 3

Data Flow Diagram Level 2 Proses 3 adalah proses infomasi Pergi Bareng yang dilakukan oleh Penumpang untuk melihat data perjalanan yang diinputkan oleh Kapten, data informasi ini diambil dari tabel Pergi Bareng.

\section{Data Flow Diagram Level 2 Proses 4}

Gambar 9 Data Flow Diagram Level 2 Proses 4 adalah proses pesan kursi yang dilakukan oleh Penumpang untuk memesan kursi perjalanan, dan data ini disimpan pada detail bareng.

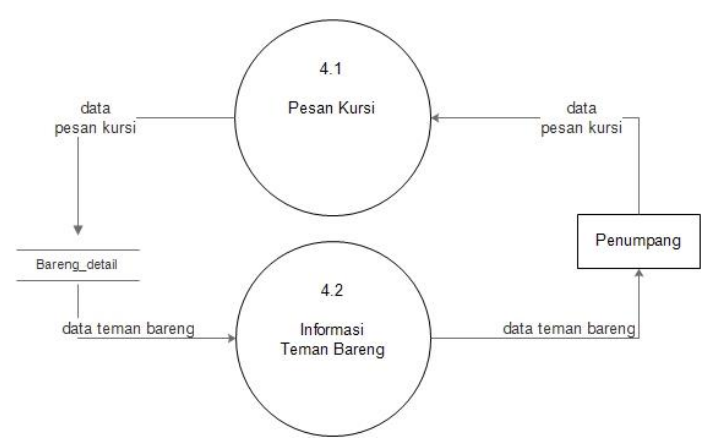

Gambar 9 Data Flow Diagram Level 2 Proses 4

\section{Data Flow Diagram Level 2 Proses 5}

Gambar 10 Data Flow Diagram Level 2 Proses 5 adalah proses yang dilakukan oleh Kapten untuk melihat data Penumpang yang ikut dalam perjalanan Pergi Bareng, data ini diambil dari detail Pergi Bareng.

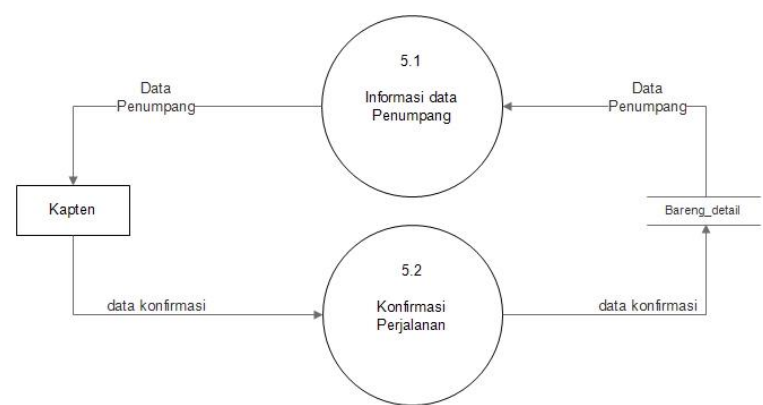

Gambar 10 Data Flow Diagram Level 2 Proses5

\section{Relasi Antar Tabel}

Relasi antar tabel rancang bangun web aplikasi Pergi Bareng dapat dilihat pada gambar 11.

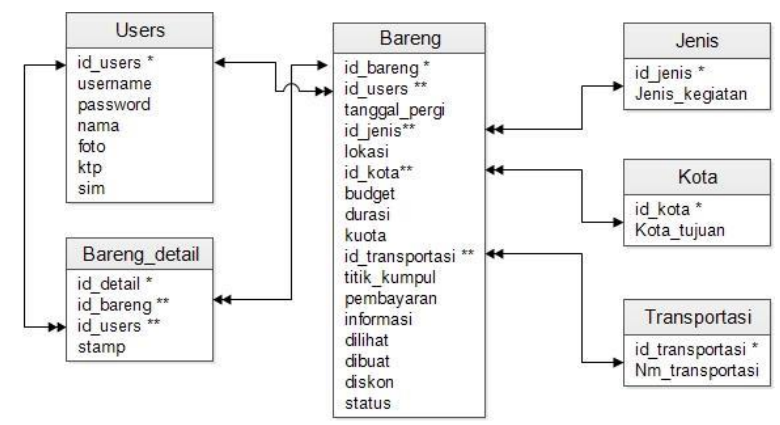

Gambar 11 Relasi Antar Tabel

\section{Arsitektur Cloud}

Arsitektur cloud computing sistem aplikasi Pergi Bareng menggunakan layanan Internet as a Services dari google. Pada arsitektur cloud computing sistem aplikasi Pergi Bareng dapat dilihat pada gambar 12. 


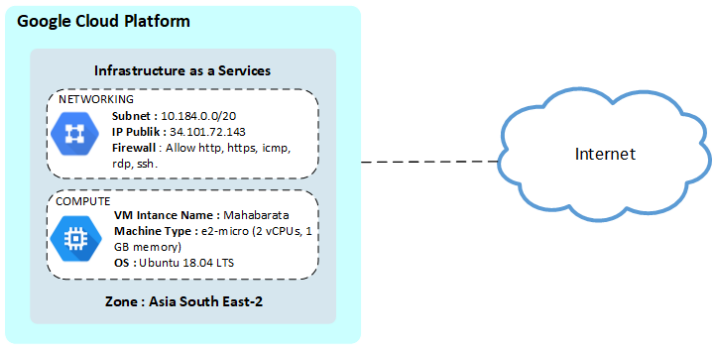

Gambar 12 Arsitektur Cloud

\section{Gambaran Umum Sistem}

Gambaran umum rancang bangun web aplikasi Pergi Bareng dapat dilihat pada gambar 13.

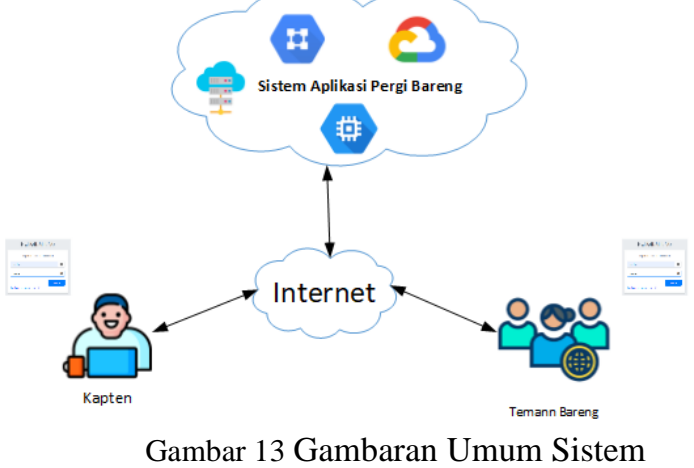

\section{Hasil dan Pembahasan}

Hasil perancangan web aplikasi Pergi Bareng ini menghasilkan suatu aplikasi yang dapat digunakan oleh pengguna untuk merencanakan perjalanan dan kegiatan dengan tujuan yang sama. Agar perencanaan kegiatan tersebut bisa dilakukan dengan bersama-sama atau berbarengan. Sistem aplikasi Pergi Bareng ini berbasis pada infrastruktur cloud computing

\section{Tampilan Web Aplikasi}

Berikut tampilan dari web aplikasi Pergi Bareng. Halaman register adalah halaman untuk mendaftar menjadi member Pergi Bareng. Halaman register dapat dilihat di gambar 14.

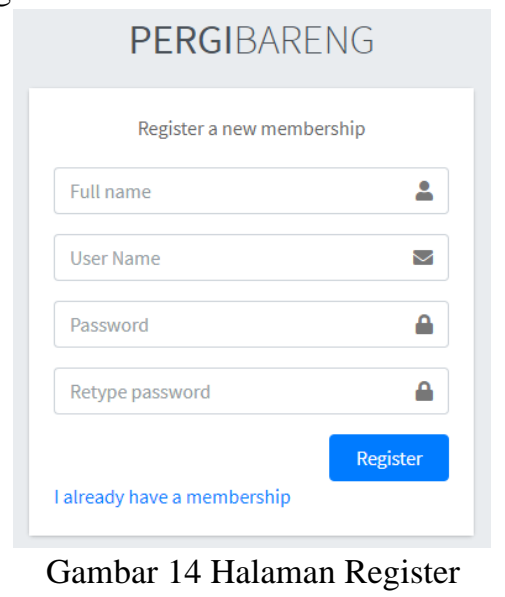

Halaman dashboard web aplikasi Pergi Bareng memuat jenis kegiatan. Halaman dashboard web aplikasi dapat dilihat pada gambar 15 .

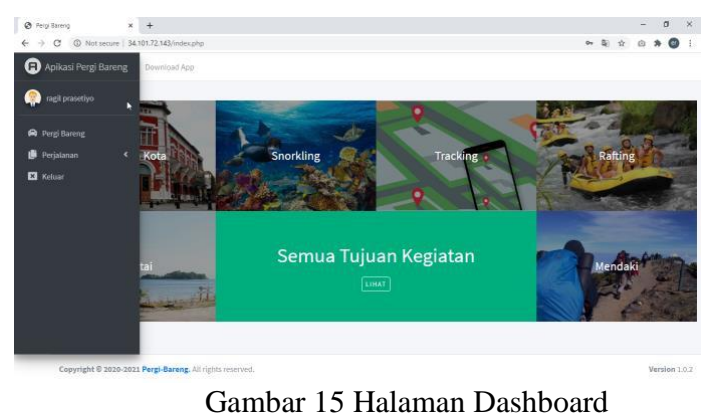

\section{Pengelompokkan Data Statistik}

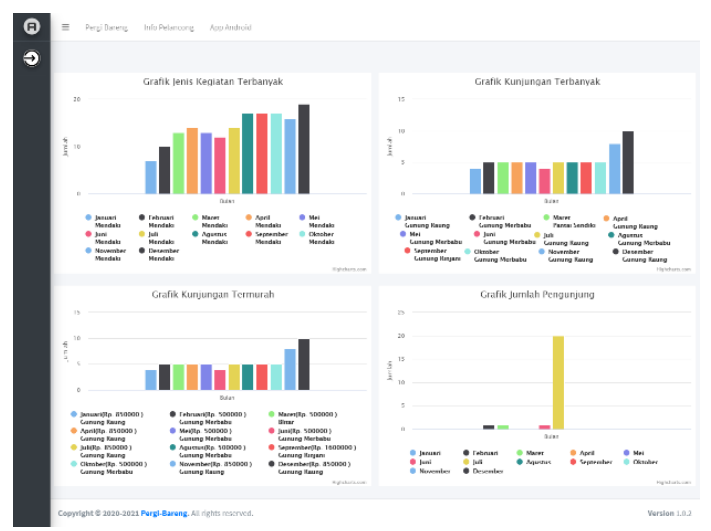

Gambar 16 Data Statistik Sistem

Pada halaman info pelancong terdapat fitur untuk menampilkan data statistik sistem aplikasi Pergi Bareng. Data yang ditampilkan adalah data statistik jenis kegiatan terbanyak, kunjungan terbanyak kunjungan termurah, jumlah pengunjung. Data dikelompokan setiap bulan. Tampilan data statistik yang ditampilkan berupa grafik, dapat dilihat pada gambar 16.

\section{Pengujian Alpha}

Pengujian alpha merupakan strategi pengujian perangkat lunak yang paling umum digunakan dalam pengembangan perangkat lunak, hal ini khusus digunakan oleh organisasi pengembangan produk dengan tujuan agar system yang dikembangkan terhindar dari cacat atau kegagalan penggunaan. Dari seluruh pengujian terhadap web aplikasi Pergi Bareng sebagai media perencanaan perjalanan dan komunikasi menggunakan metode agile berbasis cloud computing seluruh fungsi yang ditampilkan berjalan dengan baik dan sesuai dengan tujuan yang diharapkan.

\section{Pengujian Kelayakan}

Hasil uji kelayakan sistem aplikasi Pergi Bareng didapat dari data kuisioner yang disebarkan ke pegiat perjalanan wisata, dimana responden mencoba untuk mengoperasikan aplikasi ini. Dalam hasil uji kelayakan keseluruhan variabel dari responden pegiat perjalanan wisata diperoleh hasil penilaian kuisioner. Sistem aplikasi Pergi Bareng mendapat nilai keseluruhan 1915 dengan rata-rata keseluruhan 63,83 dan persentase kelayakan 85\%. Sehingga sistem aplikasi Pergi Bareng 
usabilitynya dapat dikatakan sangat layak untuk menjadi media perencanaan perjalanan dan komunikasi.

\section{Kesimpulan}

Kesimpulan yang dapat diambil dari rancang bangun web aplikasi Pergi Bareng sebagai media perencanaan perjalanan dan komunikasi menggunakan metode agile berbasis cloud computing adalah:

1. Aplikasi Pergi Bareng sebagai media perencanaan perjalanan dan komunikasi dapat mempermudah dalam mencari perencanaan kegiatan dalam satu perjalanan dengan tujuan yang sama.

2. Dengan adanya aplikasi Pergi Bareng seperti ini, maka member akan dimudahkan dalam merencanakan sebuah perjalanan sesuai dengan budget yang diinginkan.

3. Sistem aplikasi Pergi Bareng sangat layak untuk untuk menjadi media perencanaan perjalanan.

4. Dengan cloud computing perancangan sistem aplikasi Pergi Bareng lebih mudah dalam pengembangannya.

\section{Saran}

Untuk pengembangan web lebih lanjut, maka penulis menyarankan beberapa hal sebagai berikut:

1. Fitur tambahan pemilihan bahasa web untuk menjangkau customer dari luar Indonesia.

2. Perlu adanya pengembangan sistem lebih lanjut untuk dapat memenuhi semua kebutuhan user yang gemar dalam melakukan perjalanan.

\section{Daftar Pustaka}

[1] H. dkk Tolle, Jual Buku Pengembangan Aplikasi Perangkat Bergerak - Kota Malang - Toko Buku Ub Press | Tokopedia. Malang: Universitas Brawijaya Press, 2017.

[2] R. Dimas Adityo and H. Miawarni, "Penerapan Aplikasi Billing P.O.S (Point Of Sales) Berbasis Komputasi Awan Bagi Pengelola Restoran / Rumah Makan Dengan Memanfaatkan Device IoT(Internet Of Thing) Di Kab.Probolinggo Jatim," Oct. 2018.

[3] Janner Simarmata, Rekayasa Web - Janner Simarmata - Google Buku. Yogyakarta: Andi Offset, 2010.

[4] Raharjana Indra Karisma, Pengembangan Sistem Informasi Menggunakan Metodologi Agile | Yogyakarta: Deepublish. Yogyakarta: Universitas Brawijaya Press, 2017.

[5] R. S. Pressman, Software Engineering A Practitioner's Approach (SEVENTH)| New York. New York: MC Graw Hill Education, 2010.

[6] I. Gusti, Merancang Aplikasi dengan Metodologi Extreme Programmings | Jakarta. Jakarta: PT Elex Media Komputindo, 2017.

[7] A. H. (2013). R. B. S. I. A. B. U. S. Sidiq, Rancang Bangun Sistem Informasi Administrasi Beasiswa Uin Sunan Kalijaga Menggunakan Pendekatan Agile Process Dengan Model
Extreme Programming| Jakarta. Yogyakarta: Universitas Islam Negeri Sunan Kalijaga Yogyakarta, 2013 